
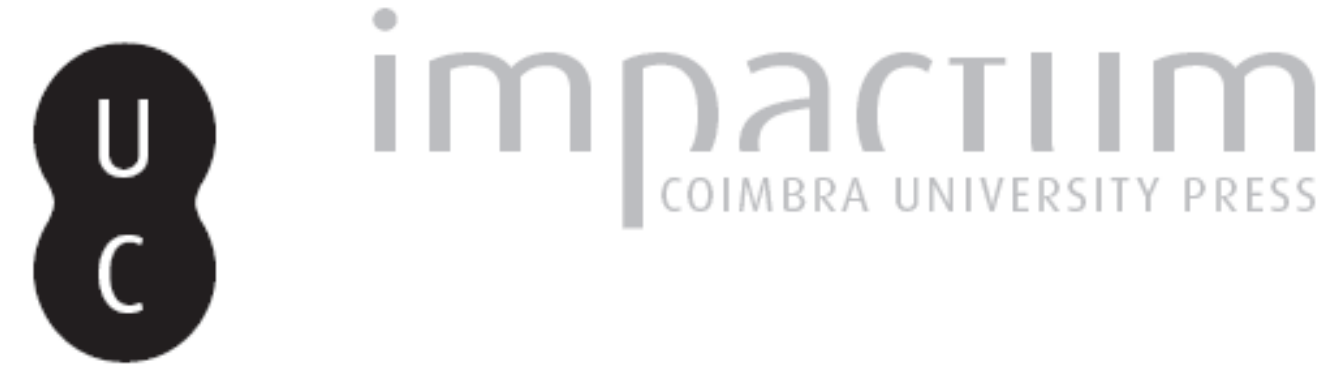

Tecnologia, georreferenciação e novas territorialidades: o caso do geocaching

Autor(es): $\quad$ Fernandes, João Luís J.

Publicado por: $\begin{aligned} & \text { Faculdade de Letras da Universidade de Coimbra, Departamento de } \\ & \text { Geografia }\end{aligned}$

URL

persistente:

URI:http://hdl.handle.net/10316.2/30216

DOI:

DOI:http://dx.doi.org/10.14195/0871-1623_31_15

Accessed : $\quad$ 26-Apr-2023 15:53:05

A navegação consulta e descarregamento dos títulos inseridos nas Bibliotecas Digitais UC Digitalis, UC Pombalina e UC Impactum, pressupõem a aceitação plena e sem reservas dos Termos e Condições de Uso destas Bibliotecas Digitais, disponíveis em https://digitalis.uc.pt/pt-pt/termos.

Conforme exposto nos referidos Termos e Condições de Uso, o descarregamento de títulos de acesso restrito requer uma licença válida de autorização devendo o utilizador aceder ao(s) documento(s) a partir de um endereço de IP da instituição detentora da supramencionada licença.

Ao utilizador é apenas permitido o descarregamento para uso pessoal, pelo que o emprego do(s) título(s) descarregado(s) para outro fim, designadamente comercial, carece de autorização do respetivo autor ou editor da obra.

Na medida em que todas as obras da UC Digitalis se encontram protegidas pelo Código do Direito de Autor e Direitos Conexos e demais legislação aplicável, toda a cópia, parcial ou total, deste documento, nos casos em que é legalmente admitida, deverá conter ou fazer-se acompanhar por este aviso.

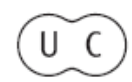




\title{
Tecnologia, georreferenciação e novas territorialidades - o caso do geocaching
}

\author{
João Luís J. Fernandes \\ Departamento de Geografia e Centro de Estudos de Geografia e Ordenamento do Território (CEGOT). Faculdade de Letras da Universidade de Coimbra. \\ jfernandes@fl.uc.pt
}

\section{Resumo:}

Quando aplicada aos transportes, a inovação tecnológica tem levado ao encurtamento das distâncias geográficas. No entanto, o desenvolvimento de plataformas digitais de socialização levantou o risco da tecnologia se associar a quotidianos mais sedentários. Ainda assim, os dados empíricos não confirmam estas teses deterministas. 0 uso democratizado das tecnologias pode ser um factor de mobilidade espacial e rompimento com o (pouco terapêutico) sedentarismo, podendo incentivar a viagem e a abertura das populações ao contacto com o espaço geográfico, seja o de proximidade, seja o mais distanciado ou remoto. É neste sentido que o geocaching, enquanto prática turística e de lazer com recente expansão, sobretudo na Europa e na América do Norte, demonstra como a utilização de novas técnicas de localização tem alterado as territorialidades dos praticantes, abrindo-os ao contacto com lugares e paisagens, alguns até então com escassa centralidade e poder de atração.

Palavras-chave: Novas tecnologias. Geocaching. Viagem. Percepção da paisagem.

\section{Résumé:}

Technologie, géolocalisation et nouveaux territorialités. Le cas du géocaching

Appliquée aux transports, l'innovation technologique a conduit à la réduction des distances géographiques. Cependant, le développement des moyens digitaux de contact social a soulevé le risque de la technologie comme un instrument néfaste qui peut encourager le sédentarisme collective. Toutefois, les données empiriques ne confirment pas ces théories déterministes. Par contre, la démocratisation de l'utilisation de la technologie peut être un facteur de mobilité spatiale et peut même encourager l'ouverture des personnes au contact avec l'espace géographique. Le géocaching, une pratique de loisir et tourisme vivant une expansion récente, surtout en Europe et en Amérique du Nord, nous montre comme l'utilisation de nouvelles techniques de localisation peut changer les territorialités personnelles avec une plus grande attraction pour des lieux inconnus.

Mots-clés: Nouvelles technologies. Géocaching. Voyage. Perception du paysage.

\section{Abstract:}

Technology, georeferentiation and new territorialities. The case of geocaching

When invested in transports, technological innovation has led to the shortening of geographical distances. However, the development of digital social networks apparently meant a serious step towards a more sedentary way of life. In fact, empirical data do not confirm these deterministic theories. Far from this negative perspective, the democratization of technology proved to be a factor of spatial mobility, avoiding the non therapeutic sedentary lifestyle and even encouraging the experience of travel. Geocaching, as a tourism and leisure practice which is growing particularly in Europe and North America, expresses how the use of new positioning techniques has changed personal territorialities, leading its practitioners to contact places and landscapes which so far revealed little centrality and attractiveness.

Key-words: New technologies. Geocaching. Travel. Landscape perception. 
Nota introdutória - a inovação tecnológica e as práticas sócio-culturais de lazer e turismo

As atividades de fruição e bem-estar estão a jusante de mudanças estruturais que abriram as sociedades a novos quotidianos que, sobretudo após a industrialização, implicaram uma diferente organização temporal (e espacial) do trabalho, da qual os tempos livres são uma das expressões (GAMA e SANTOS, 1991). A dinâmica de difusão e expansão das práticas e dos lugares de lazer e turismo, um complexo interdisciplinar social e geograficamente desequilibrado, caminhou em paralelo com o desenvolvimento tecnológico, ainda que também neste último persistam as fraturas sociais e geográficas caraterísticas de um contexto global assimétrico.

No que ao turismo diz respeito, a inovação tecnológica alterou as práticas em múltiplas vertentes. Pela compressão do espaço-tempo e pela proximidade relativa entre os diferentes lugares; pelo acesso virtual aos mesmos; pela forma como a tecnologia condiciona os métodos de construção da imagem dos destinos turísticos; pela intermediação digital entre os diferentes agentes ou pelo desenvolvimento de formas inovadoras de viajar, como o couchsurfing.

A tecnologia mudou ainda as paisagens turísticas, criou novos cenários e patrimónios e torna-se, ela própria, um objecto turístico, quer nos lugares de aplicação cenográfica desses recursos tecnológicos, como o espetáculo de luzes em Massada (Israel), quer na sua exposição lúdica e interativa, em espaços como La Villete ou o Futuroscope, em França.

As tecnologias têm também influenciado as rotinas de lazer, diversificando as opções, alterando os quotidianos, acrescentando mobilidade e flexibilidade a práticas no passado mais confinadas, abrindo-as aos espaços públicos mas também aos privados, estes agora mais híbridos. Daqui se infere que as tecnologias mudaram a relação das pessoas com o espaço. Por isso se discutem os efeitos geográficos da tecnologia. 0 desenvolvimento de redes sociais e a imaterialidade de muitas interações deu a ideia de um decrescente contacto com a natureza e com os suportes físicos da paisagem. Deixou também a aparência de que a posição geográfica perderia valor estratégico, como se fosse irrelevante estar-se aqui ou acolá. Assim se anunciou o fim da Geografia, pela diminuição do efeito de atrito do espaço geográfico, pela desvalorização das distâncias e da localização, pela imaterialidade de vidas quotidianas virtuais que se afastariam das métricas geográficas clássicas.

Contudo, a prática não tem confirmado as profecias desse determinismo tecnológico. As distâncias e as localizações importam e a tecnologia, no caso específico do lazer e do turismo, tem renovado as apropriações e o usufruto do espaço geográfico. Os jogos de localização e/ou orientação comprovam esse facto. Ainda que nem todas estas práticas impliquem o mesmo envolvimento com o terreno, todas comprovam que o progresso tecnológico e digital não fez nascer um Homem Novo a-territorial desligado do espaço.

É neste contexto da tecnologia como factor de desenvolvimento de novas sociabilidades e de outras territorialidades, que se discute o papel das tecnologias móveis em geral e dos aparelhos GPS em particular, pelas errâncias que proporcionam, pelas renovadas formas de consumo e apropriação do espaço que impulsionam.

À semelhança de outros jogos de localização, como o Mogi, o Botfighters ou o The Drop (VAlente, 2012), o geocaching tira partido das possibilidades abertas pelo desenvolvimento das tecnologias móveis, isto é, dos recursos tecnológicos utilizados enquanto o utilizador se desloca no espaço, manuseando aparelhos específicos de GPS ou outros que acrescentaram esta tecnologia a dispositivos como ocorre com os telemóveis mais sofisticados. Por isso, a difusão social e espacial desta atividade tem-se apoiado no desenvolvimento dos denominados dispositivos híbridos móveis de conexão multirredes (Lemos, 2007).

0 geocaching é um locative game que consiste na busca de um objeto georrefenciado (cache) dissimulado em diferentes contextos espaciais (FARMAN, 2009). Essa procura faz-se usando um sistema tecnológico de localização (GPS), a partir dos dados (georreferenciação) publicados num site (opencaching.com; terracaching.com ou o mais popular geocaching.com, que servirá de referência a este estudo) e recolhidos pelos utilizadoresjogadores, os denominados geocachers. Numa página web específica (alojada no referido geocaching.com), cada uma das caches é identificada por um número de código e um nome. Esses dados são acompanhados por uma notícia, com a eventual utilização de fotografias, referente ao lugar de acolhimento desse ponto. Nessa ficha podem acrescentar-se informações adicionais respeitantes ao grau de dificuldade, à dimensão do objecto ou a alguma pista mais sugestiva (hint) que facilite a busca. Na página também se encontram disponíveis os comentários de geocachers que já tenham visitado a cache no terreno.

O número, a categoria e a localização das caches dependem da opção de geocachers que, num papel misto de praticantes e owners, têm a iniciativa de, respeitando as regras atestadas por um conjunto de re- 
visores, colocarem no terreno e na plataforma digital novos pontos georreferenciados que orientem as buscas de outros geocachers. Depois da consulta on-line, realizada antes da procura, ou mesmo, cada vez mais, com o recurso a tecnologia internet wireless mais sofistada, nas proximidades do local, o geocacher parte à procura desse objeto. Após a descoberta, faz o registo em dois domínios, um analógico, no local, num logbook ali colocado para o efeito, e um outro digital, numa conta aberta pelo jogador na plataforma web, na qual também edita o registo e as impressões da experiência no terreno, acompanhadas ou não por fotografias.

É neste sentido que o geocaching será, na perspetiva da Geografia, uma atividade híbrida, pelo modo como associa duas métricas geográficas, uma euclidiana e outra topológica, a primeira expressa pelo trilhar do terreno e a segunda pela web e pelas redes digitais. É esta dimensão híbrida e, nalguns aspetos, contraditória, que também é destacada por Farman (2009, p.1): "This mobile game offers the perfect example of the blending of material and virtual interfaces, notions of presence and absence, visible and invisible, and utilitarian and playful purposes of everyday objects". Na verdade, esta prática comprova que nem sempre a tecnologia afasta do espaço geográfico as sociabilidades que se promovem no domínio virtual (Tuters e VARNelis, 2006).

Com um primeiro nível de adesão sem custos (apenas os jogadores Premium devem, no geocaching. com, pagar uma anuidade ${ }^{1}$ ), esta prática geográfica desdobra-se na organização de sites como, no caso português, o GeoPT.com, portal que, entre outros aspetos, vai publicando notícias e organizando a base estatística desta actividade em Portugal. Este mundo cruza-se ainda com a organização de grupos em redes sociais, como o Facebook, e com a manutenção de outras plataformas digitais de comunicação, como os blogues. Enquanto prática cultural de turismo e ocupação dos tempos livres, o geocaching beneficia dos sistemas sociais de troca de informações e experiências, formando grupos de partilha que, entre a internet e a experiência vivida do terreno, fazem a convergência entre as novas tecnologias de informação e localização geográfica e as regras dos jogos tradicionais de caça ao tesouro (VIANA, 2011).

A classificação desta atividade é complexa, mas trata-se desde logo de um jogo de mobilidade em espaço público potenciado pela inovação, um "nomadismo

${ }^{1} \mathrm{O}$ estatuto Premium faculta ao geocacher um conjunto diversificado de vantagens, como o acesso a algumas caches mais restritas. No entanto, qualquer jogador inscrito no site pode desempenhar um papel ativo, procurando e colocando caches no terreno. tecnológico" (VIANA, 2011, p.245) e uma prática composta entre o trabalho em plataformas digitais e as atividades outdoor, com uma componente desportiva de aventura, lazer e entretenimento, com o manuseamento de tecnologias de orientação e o desenvolvimento de tarefas que envolvem conceitos como a latitude, a longitude e a georreferenciação. Esta atividade ao ar livre pode assumir diferentes graus de dificuldade e desenvolver-se em contextos diversos, mais ou menos acessíveis, estando por isso localizada algures entre um passatempo ligeiro de escasso esforço físico e mínimo risco e uma atividade radical mais exigente.

Associado a uma prática espacial inovadora e ao desejo de novas errâncias (MAFFESolı, 2005), o geocaching pode ser uma experiência alternativa e de aventura, um dos temas e conteúdos mais representados na atual cultura de massas, com um vasto mercado, que vai da literatura de viagens ao cinema, dos parques temáticos às viagens turísticas mais ousadas. Em muitos casos abandonando as áreas de conforto, alguns segmentos do novo turismo expõem-se ao risco, seja para a descoberta de uma cache, seja pelo simples ato de rebeldia e desafio próprio. Prática de lazer e ocupação dos tempos livres, o geocaching pode, por isso, ser uma experiência turística. Assim se convoca agora o conceito de geocaching tourism - " (...) the perfect combination of travel and geocaching. Explore a new location by searching for geocaches that locals have hidden in places of general interest, historical importance and great natural beauty!"2, mais uma categoria a acrescentar às muitas que enformam o denominado novo turismo (Poon, 1994).

\section{Geocaching - difusão sócio-espacial}

A primeira cache foi colocada em Portland, nos Estados Unidos, em 2000, na sequência da decisão do governo norte-americano que, a 1 de Maio do mesmo ano, libertou o sinal GPS para uso civil. Por isso, o geocaching tem a sua origem numa tecnologia militar antes apenas acessível aos agentes norte-americanos de segurança.

No início de 2012, para um valor que rondava os 5 milhões de praticantes, estavam disponíveis cerca de 1 milhão e 600 mil caches em todo o mundo ${ }^{3}$. A distribuição geográfica destes pontos georreferenciados apresenta fortes assimetrias, com uma maior concentração

\footnotetext{
${ }^{2}$ In www.geocaching.com (consultado a 13 de Fevereiro de 2012).

${ }^{3}$ Segundo recolha efectuada no dia 5 de Janeiro de 2012 em www. geocaching.com.
} 


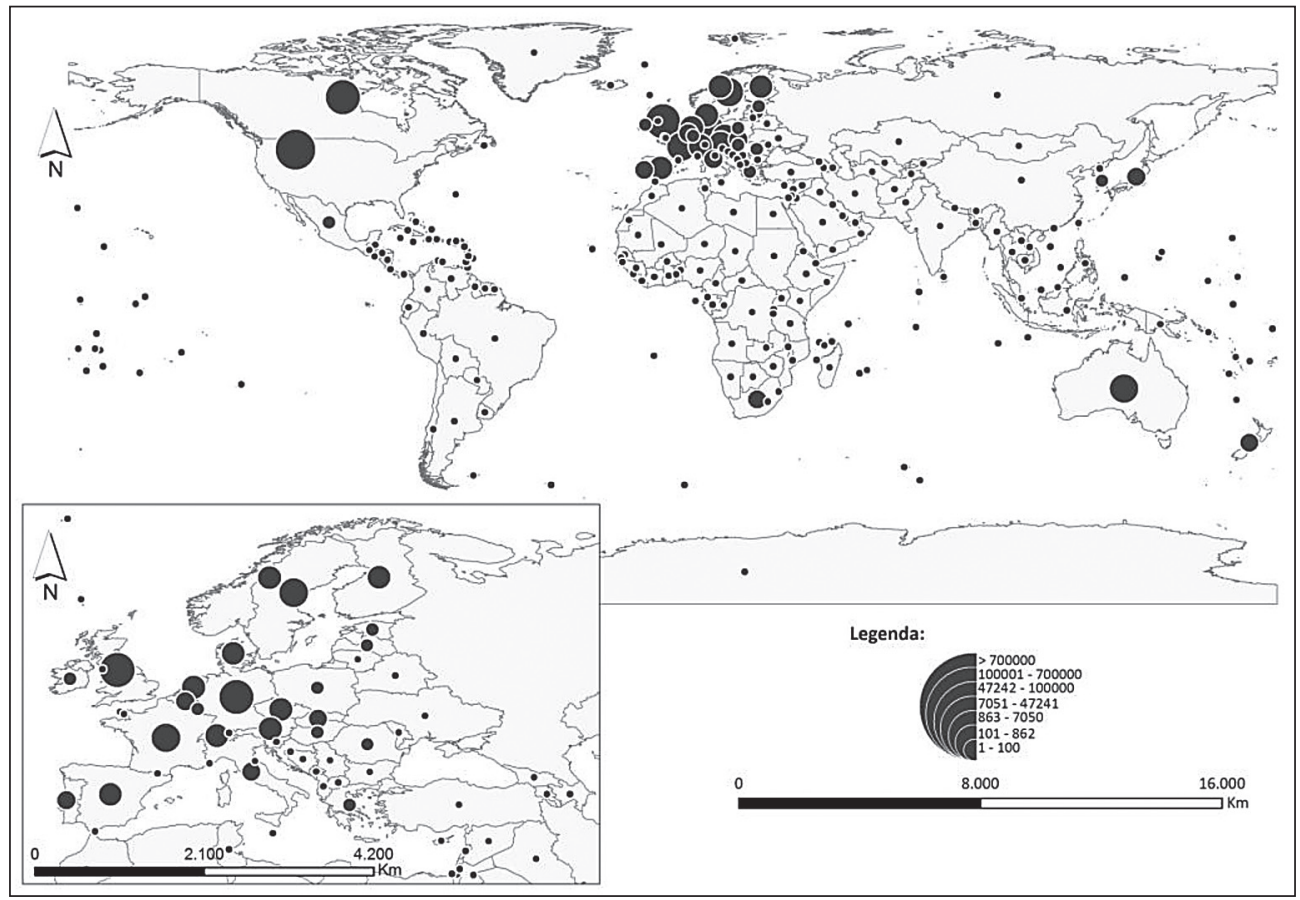

Figura 1

Distribuição espacial das caches, à escala global, em 5 de Janeiro de 2012 (a partir de dados retirados de www.geocaching.com).

na América do Norte e na Europa Central, regiões onde é superior a densidade do geocaching praticado (entenda-se, número de caches e de geocachers) (Figura 1).

Esta concentração deve-se a múltiplos fatores, como os mais elevados níveis de infoinclusão e penetração das novas tecnologias móveis de informação e comunicação e a existência de populações com maior capital de mobilidade, assim como uma mais longa tradição de atividades de turismo e lazer outdoor e fruição da natureza, através de práticas como o trekking ou o pedestrinismo. Pelas características desta prática, é importante a segurança e confiança nos espaços públicos, condição necessária para a mais efetiva promoção do geocaching. Apesar desta aglomeração espacial, existem caches em grande parte dos países do mundo, num processo de difusão muito marcado pela mobilidade de agentes como turistas, estudantes ou militares, personagens particulamente relevantes na disseminação espacial desta modalidade. Por exemplo, é notória a existência de pontos georreferenciados em espaços insulares onde se localizam bases aéreas norte-americanas. No caso português, uma das primeiras caches (a Translant Chess Cache, com o código GC8EF9) terá sido colocada, em Maio de 2001, no Arquipélado dos Açores (na Itha Terceira), por um militar dos EUA em serviço na Base Área das Lajes. Contudo, a nível nacional, o início do geocaching ocorreu no mesmo ano de 2001 com a cache GC1DA: AlfaRomeu Abandonado!, colocada na Rua das Murtas, em Lisboa ${ }^{4}$. Desde essa data, o número de caches evoluiu de forma regular, totalizando cerca de 17 mil nos finais de 2011 (Figura 2).

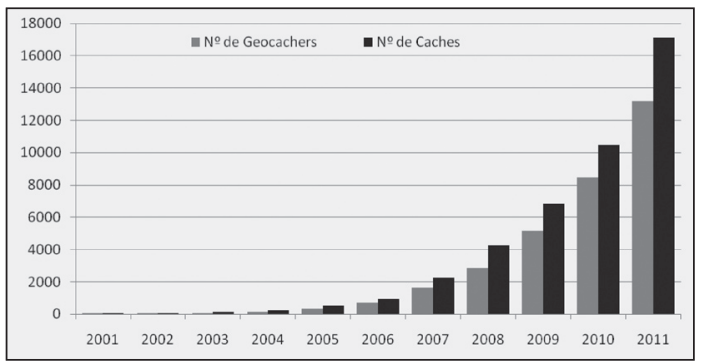

Figura 2

Evolução do número de caches e de geocachers em Portugal, entre 2001 e 2011 (a partir de dados retirados de wwwgeopt.org).

Esta dinâmica foi acompanhada, numa relação proporcional direta, pela evolução progressiva do número de geocachers que, em 2011, ultrapassava os 13 mil. No período entre 2001 e 2011, a correlação entre estas duas

${ }^{4}$ Os 10 anos desta cache e do início do Geocaching em Portugal foram celebrados, em 2011, com a cache GC22X33 -, denominada 10 Years Geocaching aka Volta Alfa estás perdoado! 
variáveis resultou num Coeficiente de Pearson de 0,998 e num Coeficiente de Determinação de $99,6 \%$, valores que comprovam a forte interdependência entre o número de praticantes e o número de caches colocadas no terreno.

Esta proporcionalidade direta não surpreende. Apesar da criação de uma cache obedecer a regras assumidas por esta comunidade, a iniciativa da sua colocação no terreno parte de um geocacher individual ou de um grupo de geocachers, pelo que o aumento destes praticantes se traduzirá no natural acréscimo de pontos no terreno. A difusão do número de praticantes em Portugal resulta, entre outros fatores, da democratização do acesso à internet e às novas tecnologias móveis de informação e comunicação que o país viveu na última década. A presente expansão do número de praticantes se é certo que resulta da maior popularidade dos desportos de ar livre e do desenvolvimento generalizado da cultura digital, é também consequência do menor custo das tecnologias de orientação no terreno, sobretudo após a entrada de equipamentos mistos no mercado.

À escala nacional, a distribuição geográfica das caches apresenta uma abrangência ampla embora com algumas assimetrias espaciais (Figura 3).

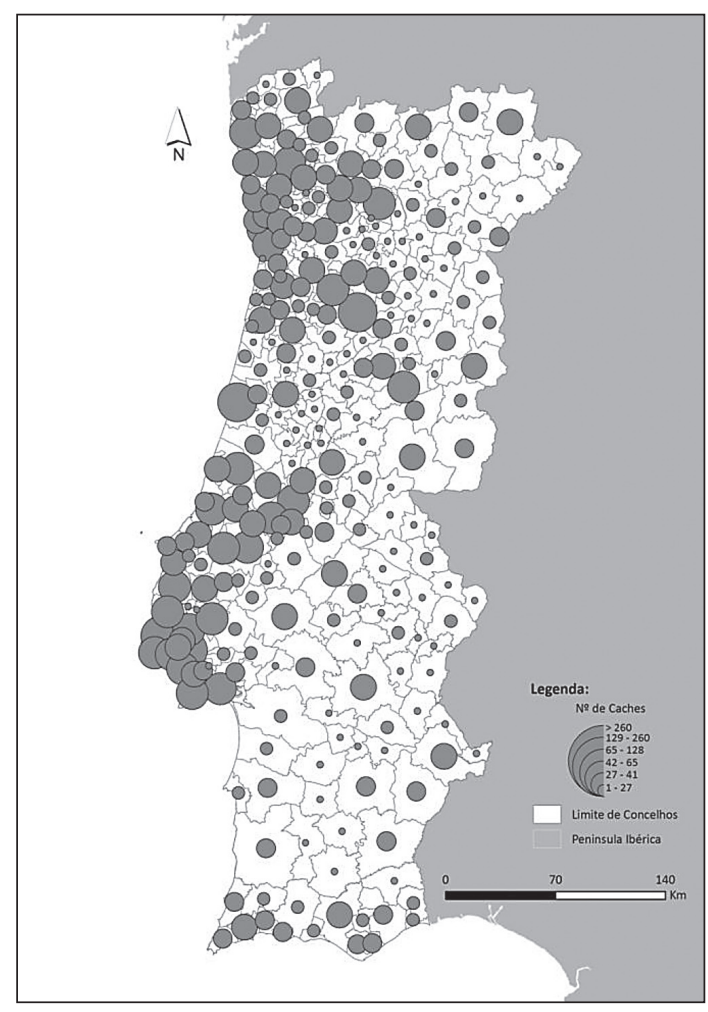

Figura 3

Distribuição das caches no território de Portugal continental, em Janeiro de 2012 (a partir de dados retirados de wwwgeopt.org).
Esta distribuição espacial, mais intensiva em torno das áreas metropolitanas de Lisboa e Porto e nalguns concelhos posicionados no corredor entre estes dois pólos organizadores do território português, é reflexo da estrutura nacional de povoamento e, também à escala local e regional, da residência de um maior número potencial de geocachers ativos. Ainda assim, numa observação mais fina, é importante destacar alguns fenómenos locais cuja relevância merecia uma análise mais pormenorizada, com é o caso dos concelhos da Figueira da Foz (402 caches no momento da contagem) e Viseu (369), com valores acima do esperado para a dimensão demográfica destes municípios, mas que resultam da sedimentação local de redes mais densas de geocachers ativos que, num círculo de indução de comportamentos, vão fazendo crescer o mapa de pontos georreferenciados em cada um dos concelhos.

\section{O geocaching enquanto experiência geográfica e de perceção do espaço}

A expansão do geocaching não depende apenas da sociedade de informação e da procura de lazeres outdoor, mas resulta também do grau de acessibilidade e segurança dos espaços públicos. Mesmo à escala global, o número de caches aumenta em lugares com espaços públicos permeáveis e seguros, diminuindo em territórios amuralhados e fragmentados por níveis menos toleráveis de segurança.

Contudo, o geocaching apropriou múltiplos lugares e ocultou caches em espaços de baixas densidades rurais e em áreas urbanas, em monumentos, jardins, muros, sinais de trânsito ou placas informativas. As caches acessíveis estão colocadas à superfície, outras, mais trabalhosas, são dissimuladas em escarpas de acesso mais condicionado, em refúgios subterrâneos ou subaquáticos ou em povoamentos florestais ou subflorestais mais fechados e inacessíveis. Nesta expressão territorial, a diversidade é muita, o que passa também pelas diferentes categorias de caches, simples algumas - a cache é o ponto de chegada último; ou múltiplas, as que obrigam o geocacher a percorrer uma rede de pontos georreferenciados até à etapa final, criando uma geocaching route que vai conduzindo o praticante por um trajeto pré-definido. A variedade é também assegurada pelos recipientes (containers) que alojam cada uma dessas caches. Se uma das condições é a sua discrição e aparente invisibilidade perante transeuntes não praticantes (na gíria desta rede social, os denominados muggles, neologismo que, a partir de Harry Potter, 
identifica os intrusos), nalguns casos os containers escondem-se em objetos paisagísticos pré-existentes (como um banco de jardim), noutros esses recipientes acrescentam-se à paisagem, que assim recebe um novo elemento, como uma planta, uma torneira, um aspersor ou uma qualquer placa de identificação falsa. Nesta construção da cache, há diferenças entre as localizações urbanas, no geral em espaços públicos mais densos; e as rurais, que permitem quase sempre uma busca mais demorada e discreta. Nesse sentido, as caches urbanas são com frequência mais simples e de acesso rápido, mais fáceis de encontrar no período noturno. Alguns geocachers preferem mesmo o silêncio e a dissimulação da noite, até porque algumas (não muitas) caches apenas podem ser encontradas descodificando diferentes sinais encriptados por ultravioletas.

Dentro da diversidade de caches e das experiências espaciais que proporcionam, há as que valorizam o ponto de chegada, facilitando o acesso mas complicando a descoberta in loco, ora com uma dissimulação mais elaborada, ora com maiores exigências e dificuldades na simples abertura desse container. Outras valorizam o percurso, convidando o praticante a uma caminhada, observando a paisagem ao longo da viagem ou mesmo no ponto de chegada, muitas das vezes um miradouro, outro dos locais onde é comum a colocação destas caches. Por outro lado, algumas caches impõem um exercício físico leve e acessível, de resto, cada uma é classificada consoante o grau de dificuldade. Outras levam o corpo ao limite, exigindo mergulho ou escalada, colocando os praticantes fora da zona de conforto, em terrenos inóspitos e pouco familiares. De uma forma ou de outra, esta prática atravessa todas as idades mas move-se no domínio do espírito infantil da aventura, da descoberta de algo que está oculto, de um tesouro que se quer desenterrar e trazer à superfície (Figura 4).

Está ainda por completar a análise sociológica desta atividade e a correta caraterização da rede de aficionados. Contudo, o arranque desta prática foi restrito e protagonizado por praticantes isolados ou organizados em pequenos grupos de jovens-adultos. A expansão quantitativa e qualitativa do geocaching abriu este jogo outdoor a faixas etárias mais alargadas, com a adesão de grupos familiares que, tal como ocorre com a maioria dos geocachers, aproveita os períodos de férias escolares e/ou laborais, quer para fazer novas inscrições na rede, quer para procurar, encontrar e regis-
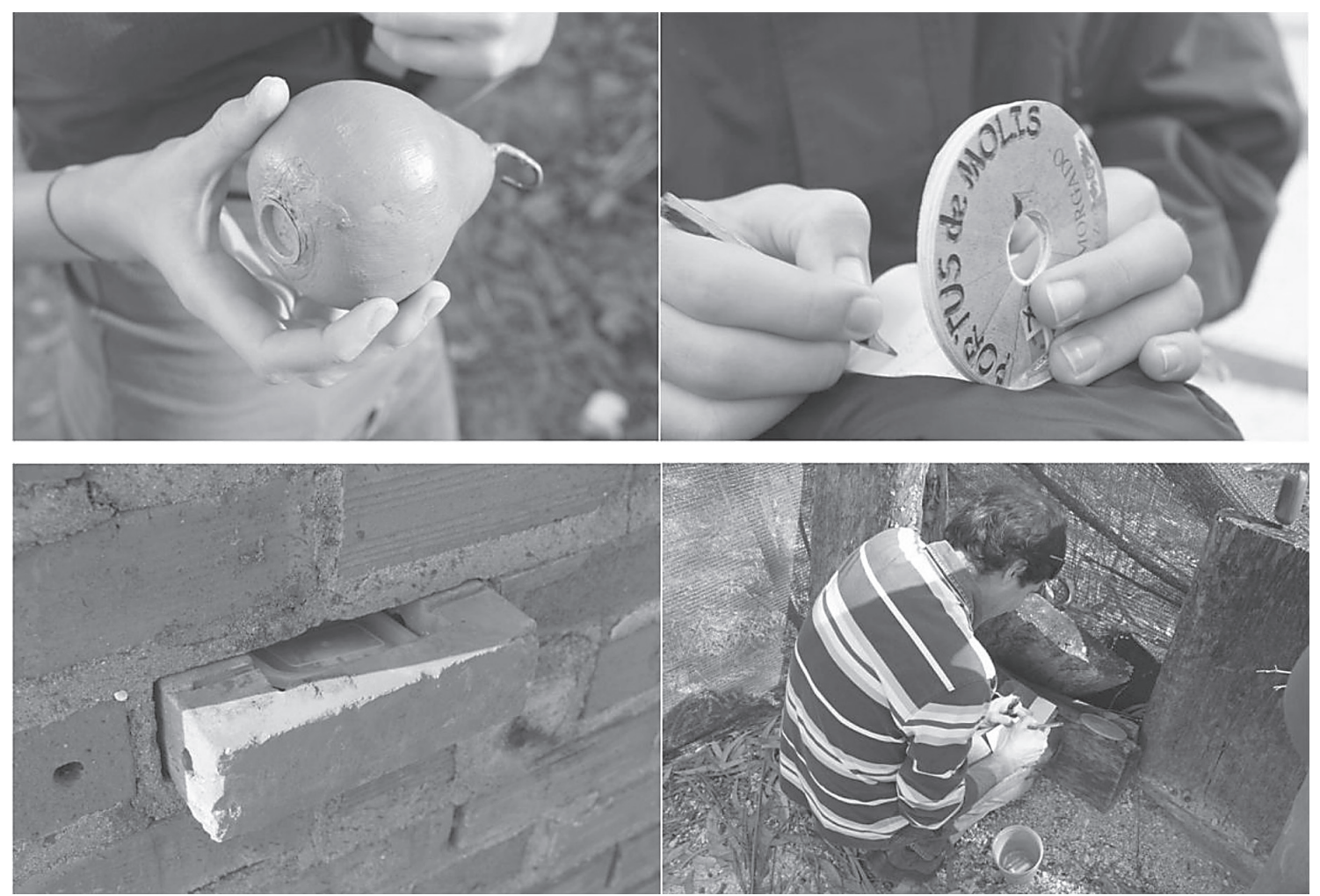

Figura 4

O geocaching em imagens: os containers, os logbooks, os lugares de dissimulação e o geocacher. 
tar os respetivos logs nas caches que se vão visitando, como se comprova nas figuras 5 e 6 , que representam valores acumulados entre 2001, o início do geocaching em Portugal, e Dezembro de 2011.

Estas variáveis apresentam uma evidente e esperada correlação, o que traduz a proporcionalidade direta entre o número de geocachers e o número de caches encontradas (e registo dos respectivos logs). Em ambas, destacam-se os meses de Verão, período por excelência das actividades outdoor, época de férias escolares e maior disponibilidade para esta prática. 0 mês de Abril, coincidente com um outro período de férias escolares, já com condições meteorológicas mais favoráveis e um dia solar mais longo, é propício à dinamização desta actividade, pelo que também neste período, em ambas as variáveis, se regista um outro máximo.

Para além das dinâmicas estatísticas, o geocaching distingue-se pelos percursos e por uma especial relação entre o geocacher e o lugar. Desde logo, os owners, responsáveis pelos pontos georreferenciados, fazem a sua própria leitura do espaço, destacando pontos que mereçam relevância e condicionando o comportamento espacial dos outros praticantes. Uma cache imprime a perceção e os conhecimentos factuais que um geocacher-owner tem sobre um lugar. 0 mapa das caches é por isso o somatório de visões parcelares de geocachers que aqui querem mostrar esta igreja, ali a sua antiga escola, acolá o lugar de brincadeiras de infância. Se bem que o geocaching se abra a geossímbolos reconhecidos (em Paris, a Torre Eiffel lá tem as suas caches), na maior parte das vezes os percursos são condicionados por geografias afectivas de owners que, por esta via, ali espacializam experiências passadas ou a este lugar chamam outros geocachers dando conta de uma leitura muito pessoal do património paisagístico que reconhece nos seus espaços mais familiares. Deste modo, o geocaching acrescenta diversidade e abre as opções a quem viaja ou faz turismo por circuitos para-

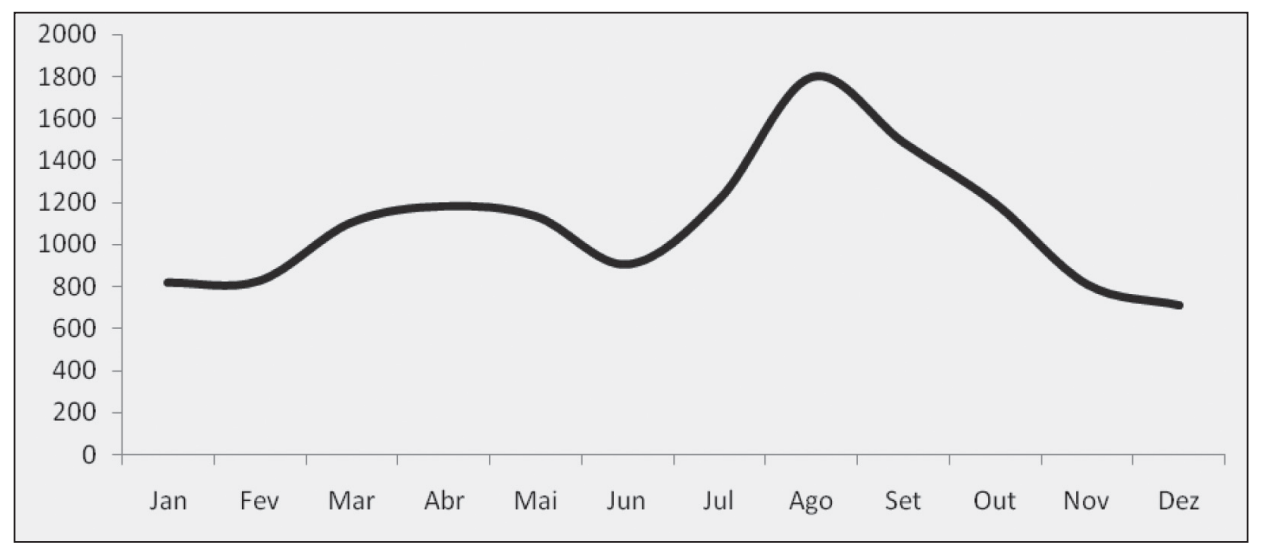

Figura 5

Evolução mensal da adesão de novos geocachers, entre 2001 e 2011 (a partir de dados retirados de wwwgeopt.org).

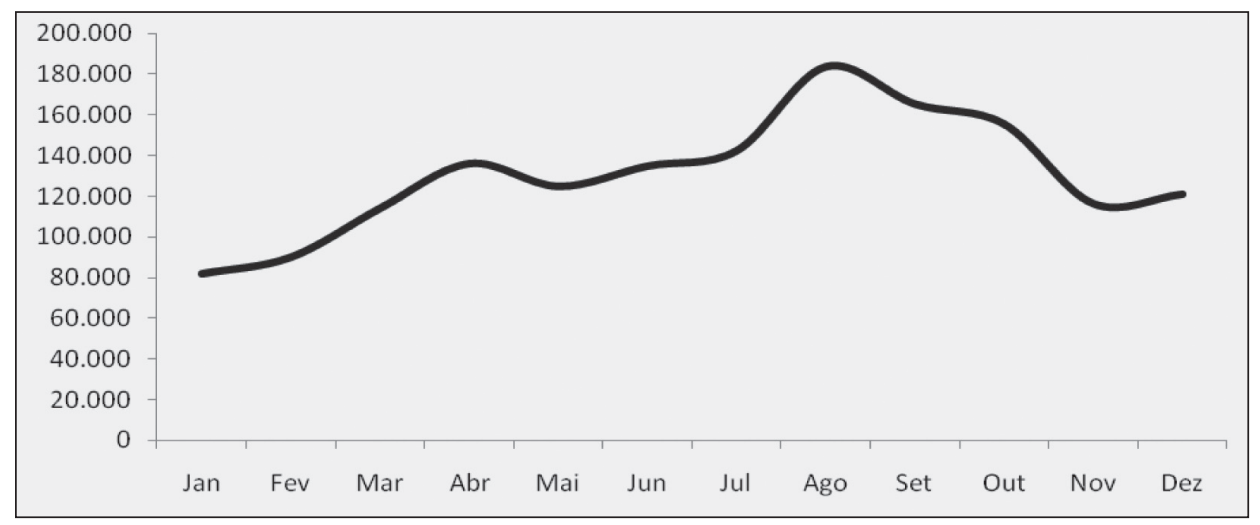

Figura 6

Evolução mensal das caches encontradas e dos logs efectuados entre 2001 e 2011 (a partir de dados retirados de wwwgeopt.org). 
lelos, no geral menos conhecidos. As novas tecnologias democratizaram a produção mas também a capacidade de difusão de conteúdos. Cada owner cria o seu próprio percurso georreferenciado, condicionando o comportamento dos outros praticantes, lendo as narrativas da paisagem, dando-lhes vida e visibilidade. Por isso, cada praticante pode, cumprindo algumas regras, registar um ponto e condicionar os fluxos. Há uma indução individual de comportamentos coletivos. Cada owner imprime a sua visão do território, chamando os visitantes para microlugares que conhece, ajudando à sua descoberta e visibilidade, lançando desafios e condicionando os mapas dos outros.

Se bem que algumas caches se decalquem de rotas turísticas já reconhecidas, outras apontam para trajectos alternativos que conduzem o geocacher por outros caminhos e pontos de observação. Por exemplo, num espaço urbano agora marcado pela rapidez, pela instantaneidade e pelo deficit de atenção para determinados microterritórios que, no quotidiano ou numa convencional visita turística, não se vêm, o geocaching, que pode ser uma prática de lentidão, convida à paragem em lugares pouco habituais e à descoberta dos pormenores, num exercício de atenção redobrada sobre a paisagem, ainda que este exercício esteja focada na descoberta do objeto. De facto, ali com uma fonte, acolá com uma pequena capela ou placa comemorativa, o geocaching orienta visitantes a lugares que já não fazem parte da territorialidade das populações, microterritórios escondidos, muitos com valor patrimonial desconhecido (ou esquecido), de um Portugal oculto pela modernidade e pela velocidade. Com a dinâmica dos tempos, a cidade afasta-se de espaços como velhas fontes e lavadouros, pontos que antes eram de encontro e agora deixaram de o ser. Resgatando-os da História, os geocachers retomam esses lugares e dão-lhe uma nova centralidade. Nesta territorialidade lúdica, o geocacher é muitas das vezes conduzido a lugares discretos e silenciosos, mas que ainda por lá estão, muitas vezes em ruínas, como símbolos de vivências que já não existem.

A relação com o espaço está marcada por hábitos repetitivos. No geral, cada um segue circuitos que já conhece, reforçando territorialidades insulares que criam áreas-sombra, espaços que não se vivem por múltiplas razões, porque não apresentam nenhum atrativo especial, porque estão protegidos por barreiras de acesso, por questões de segurança. Mesmo em áreas urbanas, a velocidade e os canais topológicos reduziram a viagem à ligação entre o ponto de partida e o de chegada, reduzindo a vivência dos pontos intermédios. É claro que o geocaching não inverte problemas de aces- so como a insegurança urbana. Contudo, esta prática resgata lugares e elementos da paisagem e convida à paragem e à observação mais atenta, nas cidades e fora delas, nos centros históricos e nas periferias suburbanas mas também nas áreas de montanha, nas margens dos rios e nos espaços rurais.

De resto, quer os espaços de altas, quer os de baixas densidades, são caraterizados pela multifuncionalidade. Por isso, se é verdade que o geocacher percorre lugares agora pouco importantes para outros atores territoriais, também acontece o contrário, isto é, lugares há nos quais o praticante de geocaching é apenas mais um protagonista no terreno, um personagem que se movimenta colidindo com outros, tentando ser mais discreto, disfarçando os seus movimentos, num jogo de invisibilidade que faz parte dos princípios do bom praticante.

Pela viagem do geocacher, pelo seu olhar, pela descrição da singularidade do lugar editada pelo owner e pela representação digital da descoberta de cada cache, através dos logs ou dos registos fotográficos, esta atividade apresenta um não negligenciável potencial de marketing territorial. Colocando o lugar no mapa dos trajetos dos geocachers, dá-se visibilidade a topónimos e a espaços geográficas até então com escassa visibilidade. Em Portugal, autarquias como Penela e Águeda têm tirado partido destas estratégias acessíveis e pouco onerosas de marketing, criando pontos georreferenciados em espaços que se pretendem divulgar.

É também nesta perspetiva que o geocaching apresenta um relevante potencial pedagógico, sobretudo em campos científicos de expressão territorial, sejam a Geografia, a História ou a Geologia, sejam áreas associadas ao turismo e ao património. Através desta prática lúdica, é possível promover uma maior cidadania geográfica, uma mais atenta leitura crítica da paisagem, definindo paragens de observação e, se for essa a opção, rotas exclusivas de pontos georreferenciados seguindo interesses específicos, sejam estes faróis, capelas, fontes, centros históricos urbanos, bairros residenciais, praias, grutas ou escarpas de falha, apenas para citar alguns exemplos.

Noutra perspetiva, enquanto experiência geográfica, o geocaching não deixa de implicar alguma transgressão. A criação e colocação de uma cache no terreno obedece a um conjunto de normas éticas importantes para regular esta atividade. Destas, destaca-se a necessária fixação da cache num local de interesse turístico, científico ou pedagógico mas de acesso público ou, caso contrário, com entrada devidamente autorizada pelo proprietário. 0 sentido de transgressão pode aqui ser 
entendido pelo modo como o geocacher se desvia da norma, se envolve com locais pouco usuais, abordandoos de forma diferente, nalguns casos pouco circunspecta - senta-se no banco do jardim mas percorre o fundo do assento na procura do tesouro escondido; aproximase da fonte mas investiga torneiras falsas, tubos disfarçados, eventualmente um orifício mal encoberto onde faz um exercício de palpação, observando o que está dentro e tentando retirar algum objeto suspeito. Em caso de sucesso, seguem-se novos gestos de dissimulação. É preciso fazer o log e recolocar a cache no local, sem suspeitas, deixando-a disponível para o geocacher seguinte.

É nesta experiência territorial que também se incorre no risco. Afinal, os gestos dissimulados podem ser mal entendidos e o geocacher confundido, criando suspeitas de ameaça à segurança do espaço público ou dos bens privado. Contudo, o risco pode derivar de uma leitura menos atenta do espaço a percorrer. É certo que cada cache indica o grau de dificuldade do terreno. No entanto, sobre a cache conhecem-se as coordenadas finais. Algumas deixam indicações adicionais sobre os percursos a seguir. A maioria não o faz, pelo que se desconhece em absoluto a trajetória.

Para além da sua relação com a Geografia, o geocaching pode ser entendido enquanto prática de socialização. Esta atividade de tempos livres e turismo sustenta-se numa rede de contactos que ocorre ao mesmo tempo em ambiente web e no terreno. Para além da prática familiar desta descoberta ao tesouro, são comuns os eventos que reúnem geocachers e promovem oportunidades de estreitamento social, troca de informações ou mesmo a criação de projetos comuns de procura e colocação de novas caches.

Em suma, o geocaching é uma realidade estatística em progresso, com um evidente aumento de praticantes. A popularidade desta modalidade de turismo e tempos livres deve-se às redes sociais e ao embaratecimento e multifuncionalidade das tecnologias GPS. Por aqui se comprova que o desenvolvimento tecnológico não promove uma cultura a-territorial nem necessariamente afasta os utilizadores da fruição do espaço geográfico. Pelo contrário, promovem-se as atividades ao ar livre e novas relações espaciais, estimula-se a orientação, a (re)descoberta de lugares, o reforço de velhos trajetos ou a opção por novos caminhos e paragens. Daqui vai emergindo uma nova categoria turística. Em época de diversificação e segmentação de produtos e procuras e de mudança nos velhos paradigmas do turismo massificado, o geocaching será uma atividade extra que se acrescenta a experiências turísticas diver- sificadas. Noutros casos, a prática do geocaching é a razão mesma e a motivação essencial de uma viagem turística. Contudo, muito há ainda por estudar nestas práticas. São muitos e diversificados os interesses e os termos da relação do geocacher com o espaço. Nada se pode generalizar, sobretudo o modo como cada lugar se arreiga no praticante. Alguns ali pararão sem observar. A paragem é um mero registo e uma passagem para a cache seguinte, que deve ser descoberta sem delongas, para depois se seguir uma outra, até ao limite do possível. Ao mesmo tempo, para outros geocachers, o exercício é mais lento e demorado. Nestes, para além da descoberta do tesouro, vale o lugar, a sua individualidade, as narrativas que justificaram a viagem. A cache é um pretexto de observação da paisagem. Uma oportunidade para registar, com uma fotografia, o momento e as vistas. De qualquer dos modos, ali se criou uma nova centralidade, a partir dali se difundiram as experiências e se induziram outros praticantes a decalcar os mesmos passos. Por isso o geocaching é um fenómeno espacial: porque cruza o espaço geográfico com a mobilidade espacial; porque condiciona os movimentos e os olhares sobre a paisagem; porque define territorialidades muito específicas, estranhas e mesmo intrigantes - o geocacher pode ter um comportamento diferente, por vezes até suspeito, movimenta objetos, ajoelha-se no solo, arrasta-se por baixo de arbustos, levanta rochas mais ou menos pesadas, coloca a mão nos troncos ocos de árvores ou escala rochedos íngremes, investiga o verso dos sinais de trânsito, espreita os telhados mais rasteiros, observa o que está por detrás dos muros. Independentemente disso, o geocacher é apenas um novo protagonista, um outro alguém que se movimenta na paisagem e a apropria.

\section{Bibliografia}

EsCLASSE, Pierre (2004) - Aprenda a orientar-se. Col. Aventura \& Viagens, Publicações Europa-América, Lisboa.

FARMAN, Jason (2009) - "Locative Life: geocaching, Mobile Gaming, and Embodiment". Proceedings of the Digital Arts and Culture Conference - after media: embodiment and context, University of California, Irvine.

Fitzsimons, Vincent G. (2011) - "The impact of new technologies on leisure networks". In: CAMERon, S. (ed.) - The Handbook on the Economics of Leisure. Edward Elgar.

Gama, António e Santos, Norberto Pinto dos Santos (1991) - "Tempo Livre, Lazer e Terciário". Cadernos de Geografia, n¹0.

MAFFESOLI, Michel (2005) - El nomadismo. Vagabundeos iniciáticos. Fondo de Cultura Económica, México. 
Poon, Auliana (1994) - "The new tourism revolution". Tourism Management, vol. 15, issue 2 .

Tuters, Marc e Varnelis, Kazys (2006) - "Beyond Locative Media: Giving Shape to the Internet of Things". Leonardo, 39(4).

VALENTE, Luís (2012) - "Jogos baseados em localização para telefones celulares: Exemplos de estratégias para tratar limitações tecnológicas", em www-di.inf.puc-rio.br (acesso no dia 8 de Fevereiro).

VIANA, Joana Alencar (2011) - "A mobilidade como aventura na cidade: jogos baseados em geolocalização (gps) e apropriação urbana”. Movimento, vol. 17, $\mathrm{n}^{\circ} 1$. 